\title{
The Study of the Structural, Morphological, and Mechanical Characteristics of the Laser-Irradiated Aluminium Targets
}

\author{
Wajeehah SHAHID ${ }^{1}$, Samiah SHAHID $^{2}$, Syed ZAHEER UD DIN ${ }^{3,4 *}$, Wentao WANG $^{4}$, \\ Wei CHENG ${ }^{4}$
}

${ }^{1}$ Department of Physics, The University of Lahore, Lahore 54000, Pakistan

${ }^{2}$ Institute of Molecular Biology and Biotechnology, The University of Lahore, Lahore 54000, Pakistan

${ }^{3}$ International School for Optoelectronic Engineering, Qilu University of Technology (Shandong Academy of Sciences), Jinan 250353, China

${ }^{4}$ Laser Institute, Qilu University of Technology (Shandong Academy of Sciences), Jinan 250104, China

crossref http://dx.doi.org/10.5755/j02.ms.27542

Received 02 September 2020; accepted 13 October 2020

\begin{abstract}
Aluminium samples are irradiated using a continuous-wave diode laser in a laboratory environment to study the effect on its surface, structural, and mechanical properties. The exposed samples are investigated by scanning electron microscopy and x-ray diffractometer for the surface and structural morphology, respectively. The scanning electron microscopic analysis unveils the realization of micrometer grain size, exfoliational sputtering, and crater production. The diffractometric $x$-ray analysis reveals the grain size, d-spacing, and dislocation line density of the targeted samples. The hardness of the samples as a function of exposure time is investigated using the micro Vickers hardness tester to perceive the mechanical properties. An increase in micro-hardness is observed with the increase in the exposure time.

Keywords: aluminium, CW diode laser, SEM, XRD, Vickers hardness test.
\end{abstract}

\section{INTRODUCTION}

Aluminium ( $\mathrm{Al})$, being the prime material uses in the construction of the aircraft industry, even titanium, and its composites are growing in use, about $70 \%$ of the commercial aircraft frames are made of $\mathrm{Al}$ alloys [1, 2]. The use of lightweight materials is highly encouraged by the climate warnings, environmental awareness, and high fuel prices in the transport industry. The $\mathrm{Al}$ and its alloys are widely used in commercial transportations, railcars, marine exteriors, and defense vehicles due to its acceptable cost, good strength to weight ratio, appropriate mechanical properties, structural integrity, and ease of fabrication [3]. However, the increasing demand for engineering materials for the desired mechanical properties leads to an increased interest in the surface modification of the materials [4]. There are different surface modification techniques available [5-10]. However, considering the improvement of the surface properties, the laser irradiation technique has advantages because it is widely used in the microstructural modification of the surface layer in surface engineering $[4,11-14]$.

The laser irradiation treatment significantly enhances the hardness of aluminium-silicon alloy reported by Nassar and his coworkers [15]. Hussein et al. treated the $\mathrm{Al}$ alloy using Nd: YAG laser and found an increase in its microhardness [16]. Pinto et al. (2003) described that the average increase in hardness of the dendritic structure $\mathrm{Al}$ is more than that of the cellular structure [17]. The hardness of the steel can be increased by reducing the thickness of the sample and at the slow-scanning speed [18]. Elkandari et al.
(2013) studied the corrosion-resistant of $\mathrm{Al}$ using an excimer laser and found that the laser treatment causes reheating in the sample [19]. The laser-treated surface area is based on the heating caused by the light adsorption if the surface layer and the cooling guaranteed by the high conductivity of the sample. The cooling results in a thin layer, which is different from bulk materials, and that leads to the improvement of the physical properties of the sample [20]. This rapid cooling of the $\mathrm{Al}$ has some advantages such as the reduction in the microsegregation and modification of the microstructure [4, 21, 22].

This work involves the effect of the continuous-wave (CW) diode laser on the surface, structural, and mechanical properties of $\mathrm{Al}$ in a laboratory environment, which has vital importance in several industries. The specimens are irradiated and investigated for different exposure time using $532 \mathrm{~nm}$ wavelength using scanning electron microscopy (SEM) and x-ray diffractometer (XRD) for the surface and structural morphology, respectively. The SEM analysis reveals the realization of micrometer grain size, exfoliational sputtering, and crater. The morphology of surface structures is allied with a change in laser irradiation time. The appearance of the formation of the random microstructure is seen significantly. It is observed that the material is speckled out during the laser irradiation, which is attributed to the fact that laser produces thermal stresses, cracks, and surface roughness. The grain size, d-spacing, and dislocation line density of the irradiated samples are studied using XRD analysis. It is perceived further that the grain size is increased with the increase in the exposure time. The mechanical properties of the irradiated samples

\footnotetext{
* Corresponding author. Tel.: +86 18563721939.

E-mail address: zaheer@qlu.edu.cn (S. Zaheer Ud Din)
} 
are investigated by employing micro Vickers hardness tester. An increase in micro-hardness is investigated by increasing the time of laser exposure.

\section{EXPERIMENTAL METHODS}

The schematic diagram of the experimental setup is shown in Fig. 1; here, Al, with the purity of $99.999 \%$ is used as a target sample.

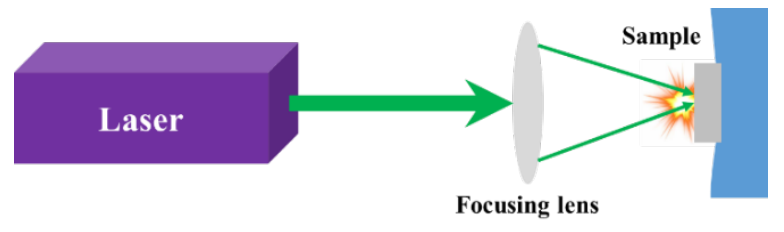

Fig. 1. Schematic diagram of the experimental setup

The rectangular-shaped highly polished, $\mathrm{Al}$, samples $(2 \mathrm{~mm} \times 2 \mathrm{~mm} \times 2 \mathrm{~mm})$ are irradiated with $\mathrm{CW}$ laser, which is operated at the energy density of $3.5 \mathrm{~J} / \mathrm{cm}^{2}$ and wavelength of $532 \mathrm{~nm}$ with time variation. The irradiation is performed in the air. For the precise arranging of samples for each exposure, the targets are attached to a holder enabled with the xyz-manipulator with the capability to move $5 \mu \mathrm{m}$ in each ( $\mathrm{x}, \mathrm{y}$, and $\mathrm{z}$ ) direction. The laser beam is made incident perpendicular to the surface of the target using a focusing lens of $13 \mathrm{~cm}$ focal length, $\pm 1.0 \mathrm{~nm}$ wavelength stability $1.33 \mathrm{~mm}$ spot size, Gaussian profile, power output vs. temperature of $<5 \%{ }^{\circ} \mathrm{C}$, and $1-200 \mathrm{~mW}$ single-mode optical power range. A surface area of approximately $2 \mathrm{~mm} \times 2 \mathrm{~mm}$ is irradiated by overlapping individual laser spots. A laser beam with a Gaussian line profile is used, which means that different energy density levels occur within the irradiated target area. This, in turn, resulted in different structures and morphologies in the different areas of the spot (at centers). Investigation of the surface topography of the laser-irradiated samples is performed with the SEM. The SEM analysis is carried out to probe the surface modification, and structural analysis is measured with the XRD techniques.

\section{RESULTS AND DISCUSSION}

\subsection{SEM analysis}

A delicate SEM model (Fei, Quanta250) with high resolution is used in this study. The thermal effects on the surface topography of the irradiated samples are involved. The structural changes with time variations laser-irradiated samples are observed through the SEM analysis. The image appearing in Fig. 2 a shows the SEM micrograph of untreated $\mathrm{Al}$ target at $1000^{\mathrm{X}}$. The horizontal periodic scratches, uniformity of surface roughness without laser irradiations are very clear on the target surface. This may be due to the fact that the surface is not fine polished. Fig. $2 \mathrm{~b}$ shows 20 minutes of exposure of the diode laser at $1000^{\mathrm{X}}$. The morphology of surface structures is associated with the change in laser exposure time. The distribution of random microstructures formation is visible in this image. The appearance of these microstructures is deposited and is significantly clear. The shape of these microstructures is irregular. Montross et al. (2002) reported that the laser shock treatment could meaningfully increase the performance of fatigue, hardness, and mechanical properties of some metals and alloys [23].

The laser ablation of a solid target in the occurrence of ambient gas has conquered a significant status because of its vast applications, e.g., pulsed laser deposition, nanoparticle production, and laser-induced spectroscopy [24, 25]. The microstructures demonstrate the redeposit of the materials. The redeposition of the material occurs on the surface due to the CW laser, which indicates the absorption of laser, heat conduction, and energy exchange. At the exposed spot, exfoliation formation is also observed. Earlier it is reported that during the laser ablation of materials, the natural surroundings and pressure of the ambient atmosphere are controlling features of plasma appearances as well as aspects associated to the laser energy absorption for surface variation [24, 26]. Preuss et al. (1995) investigated the performance of laser ablation on different metals like nickel, copper, molybdenum, indium, tungsten, and gold in the presence of air atmosphere and vacuum [27]. They suggested that the ablation of metal in the air is much less efficient than in a vacuum due to the redeposition effect and shield material removed. Pedraza et al. (2000) examined the result of numerous environments of air, oxygen, and nitrogen on nano/micro-structuring and growth of microcolumns on the surface of silicon [28]. Fig. $3 \mathrm{c}$ illustrates the significant heat conduction for 40 minutes at $1000^{\mathrm{X}}$. The CW laser produces a plasma plume near the surface with a maximum density of ions, electrons, and atoms. It is obvious from the figure that material is splashed out from the laser irradiation. This is attributed to the fact that the laser produces thermal stresses, cracks, and surface roughness. After 40 minutes of laser irradiation, surface melting is observed. The thermal stresses are the root cause of these cracks.

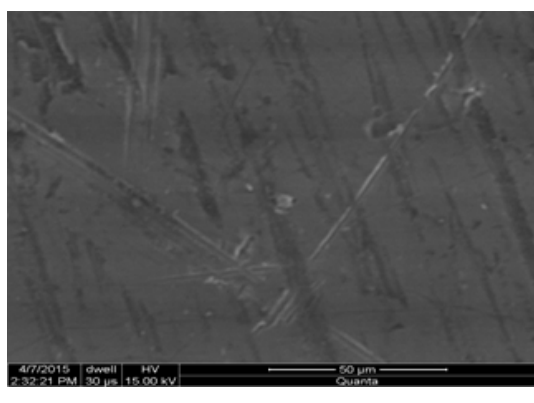

a

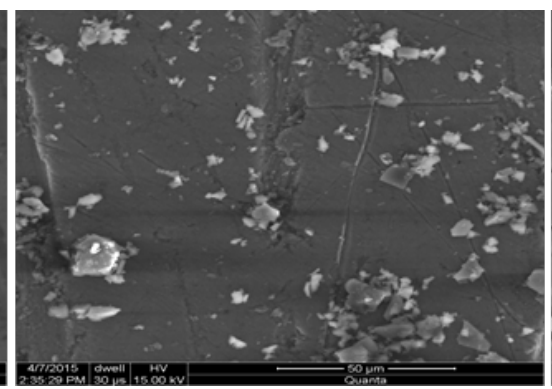

b

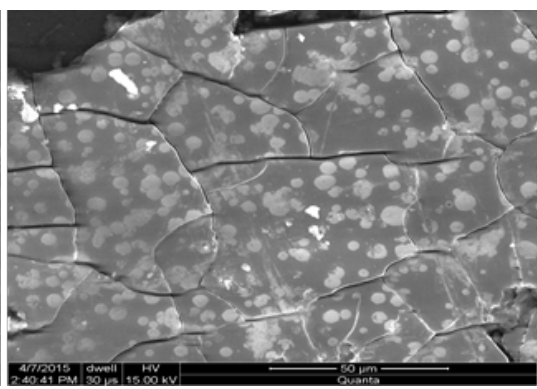

C

Fig. 2. SEM micrographs of $\mathrm{Al}$ target: a - unexposed $\mathrm{Al}$ at $1000^{\mathrm{x}}$; b -20 minutes exposed at $1000^{\mathrm{x}}$; c-40 minutes exposed at $1000^{\mathrm{X}}$ 
The simple arrangement is that the material meltdown under deformation and eventually after treatment solidifies, making the distortion permanently. Mahmood et al. (2010) investigated that by increasing the laser influence, the processes like melting and recrystallization takes place [29]. Due to the hydro-dynamical effects cooling and crystallization of metals resided in the irradiated zone generate intense boiling. After melting and boiling, the material re-solidifies, and solute oxygen atoms diffuse and segregate to grain boundaries along with the formation of oxides.

\subsection{XRD analysis}

\subsubsection{Unexposed Al target}

Fig. 3 a shows the unexposed $\mathrm{Al}$ sample of XRD patterns. Four peaks of Al sample at $2 \theta=38.5^{\circ}, 44: 75^{\circ}$, $65: 25^{\circ}$, and $78.25^{\circ}$ are obtained, the corresponding data can be seen in Table 1 .

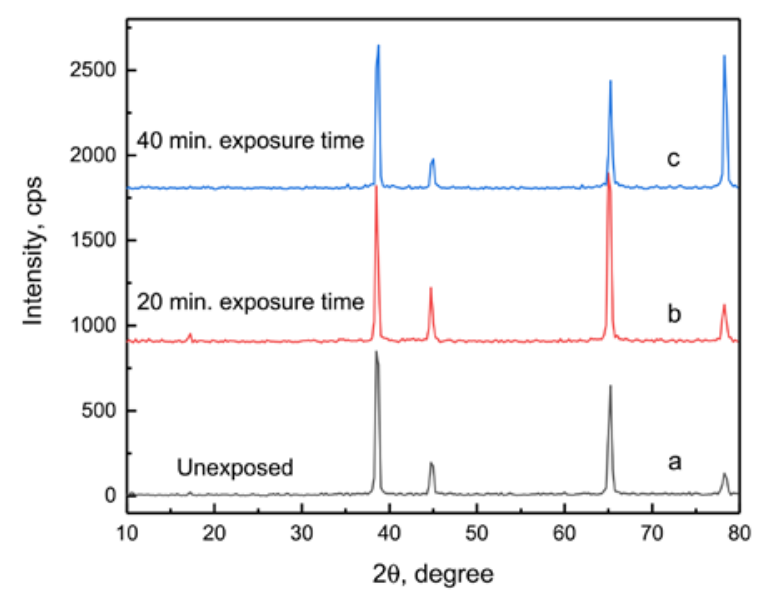

Fig. 3. The XRD patterns of the $\mathrm{Al}$ sample, a-unexposed $\mathrm{Al}$ sample; b-20 minutes irradiated sample; c -40 minutes irradiated sample

It is confirmed that $\mathrm{Al}$ has a polycrystalline nature with (111), (002), (022), and (333) hkl planes of reflection, respectively. The grain size and relative intensity of $\mathrm{Al}(111)$ peak are $2.94 \AA$ and $100 \%$, respectively. For the plane (022), the values of the above-mentioned parameters are $2.84 \AA$ and $76.29 \%$, respectively. For $\mathrm{Al}$ (333), the grain size and relative intensity $3.03 \AA$ and $15.56 \%$, respectively. The dislocation line density of $\mathrm{Al}(111), \mathrm{Al}(002), \mathrm{Al}(022)$, and $\mathrm{Al}(113)$ peaks is $1.16 \times 10^{19}, 7.48 \times 10^{18}, 1.24 \times 10^{19}$, $1.09 \times 10^{19}$, respectively. The d-spacing of corresponding peaks are $2.336 \AA, \quad 2.0237 \AA, \quad 1.4288 \AA, \quad 1.220 \AA$, respectively.

\subsubsection{0 minutes laser exposure}

Fig. $3 \mathrm{~b}$ shows the XRD patterns of $\mathrm{Al}$ target irradiated by CW laser for 20 minutes (see Table 2 for the corresponding data). The four peaks of cubic $\mathrm{Al}$ crystal at $2 \theta=38.51^{\circ}, 44.76^{\circ}, 65^{\circ}$, and $78.25^{\circ}$ can be clearly seen. The grain size and relative intensity of $\mathrm{Al}(111)$ peak are $3.97 \AA$ and $92.269 \%$, respectively, of $\mathrm{Al}(002)$ peak is $3.94 \AA$, and $32.314 \%$, respectively, of $\mathrm{Al}(022)$ peak are $3.35 \AA$ and $100 \%$, respectively, of $\mathrm{Al}(113)$ peak is $3.08 \AA$ and $22.513 \%$, respectively. The dislocation the line density of $\mathrm{Al}(111), \mathrm{Al}(002), \mathrm{Al}$ (022), $\mathrm{Al}$ (113) peaks are $6.35 \times 10^{18}$;
$6.43 \times 10^{18} ; 8.89 \times 10^{18} ; 1.05 \times 10^{19}$, respectively. The dspacing of corresponding peaks are $2.33 \AA$, $2.023 \AA$, $1.42 \AA$, and $1.22 \AA$, respectively.

\subsubsection{0 minutes laser exposure}

Fig. 3 c demonstrates the XRD patterns of the $\mathrm{Al}$ target exposed to CW laser for 40 minutes. The grain size and relative intensity of $\mathrm{Al}(111)$ peak are $3 \AA$ and $100 \%$, respectively and of $\mathrm{Al}(002)$ peak are $2.88 \AA$ and $21.065 \%$, respectively and of $\mathrm{Al}(022)$ peak is $4.45 \AA$ and $75.73 \%$, respectively, and of $\mathrm{Al}$ (113) peak are $4.15 \AA$ and $92.78 \%$, respectively. The dislocation line density of $\mathrm{Al}(111)$, $\mathrm{Al}(002), \mathrm{Al}(022), \mathrm{Al}(113)$ peaks are $1.11 \times 10^{19}, 1.2 \times 10^{19}$; $5.06 \times 10^{18}, 5.8 \times 10^{18}$, respectively. The d-spacing of corresponding peaks are 2.321 $, 2.013 \AA, 1.428 \AA$, $1.220 \AA$, respectively (see Table 3).

The grain size is increased with the increase in the exposure time. The grain size is smaller for untreated samples, but it slightly increases when exposes for 20 minutes, while the maximum size can be seen when exposes for 40 minutes. Due to the increase in grain size, the material is becoming softer, and its crystallinity improved. The maximum intensity is about 996 (cps) observed at 20 minutes laser irradiation. There is a variation in the intensity of the observed peaks, which is because of the scattering effects and not uniformity, recrystallization, and driving non-uniform thermal stresses of the energy absorbed by the atoms due to the laser-matter interaction [30, 31]. Initially, the peak intensity increases with the increase in the exposure time. This rise in peak intensity is credited to the improvement of the diffraction of X-ray from target and the crystal development due to atomic dispersion through the grain boundaries after laser irradiation. By increasing 20 minutes of exposure time, the intensity of diffracted peak decreases. More increasement in the irradiation time causes more reduction in the intensity of the peak. The resolidification and recrystallization phenomena occur due to the reduction in the intensity of diffracted peaks. Largesized grains break up into the smaller ones after laser irradiation and cause a decrease in the peak intensity [32].

\subsection{Micro-hardness test}

Fig. 4 represents the variation of micro-hardness of $\mathrm{CW}$ laser irradiated $\mathrm{Al}$ as a function of time.

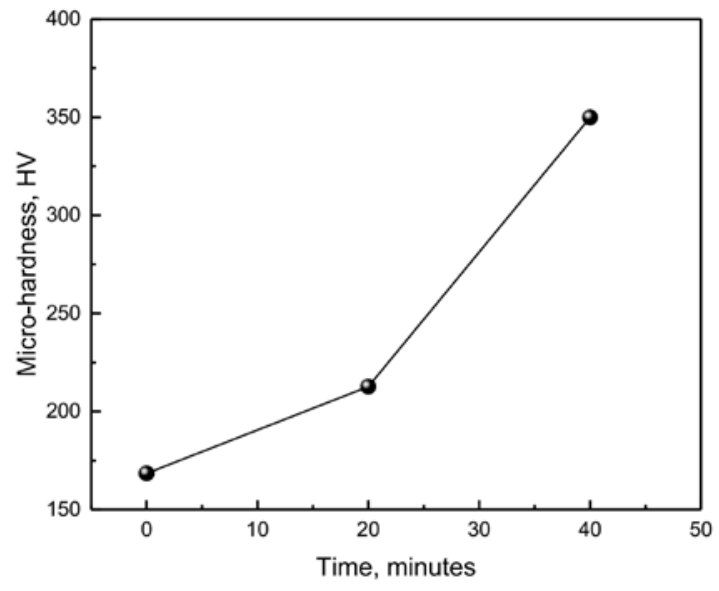

Fig. 4. Vickers hardness test of $\mathrm{Al}$ 
Table 1. XRD data of unexposed $\mathrm{Al}$ sample

\begin{tabular}{|c|c|c|c|c|c|c|c|c|c|}
\hline Peak No. & $2 \theta$ (degree) & $d, \AA$ & $h k l$ & $I$ & $I(\max )$ & $I($ rel) & FWHM & G.S, $\AA$ & DLD \\
\hline 1 & 38.50 & 2.336 & 111 & 848 & 848 & 100 & 0.50 & 2.94 & $1.16 \times 10^{19}$ \\
\hline 2 & 44.75 & 2.023 & 002 & 196 & 848 & 23.11 & 0.41 & 3.66 & $7.48 \times 10^{19}$ \\
\hline 3 & 65.25 & 1.428 & 022 & 647 & 848 & 76.30 & 0.58 & 2.84 & $1.24 \times 10^{19}$ \\
\hline 4 & 78.25 & 1.220 & 113 & 132 & 848 & 15.56 & 0.59 & 3.03 & $1.09 \times 10^{19}$ \\
\hline
\end{tabular}

Table 2. XRD data of 20 minutes of laser exposure of $\mathrm{Al}$ sample

\begin{tabular}{|c|c|c|c|c|c|c|c|c|c|}
\hline Peak No. & $2 \theta$ (degree) & $d, \AA$ & $h k l$ & $I$ & $I(\max )$ & $I($ rel) & FWHM & G.S, $\AA$ & DLD \\
\hline 1 & 38.51 & 2.336 & 111 & 919 & 996 & 92.30 & 0.37 & 2.97 & $6.35 \times 10^{18}$ \\
\hline 2 & 44.76 & 2.023 & 002 & 321.85 & 996 & 23.31 & 0.38 & 3.94 & $6.43 \times 10^{18}$ \\
\hline 3 & 65 & 1.433 & 022 & 996 & 996 & 100 & 0.49 & 3.35 & $8.89 \times 10^{18}$ \\
\hline 4 & 78.25 & 1.220 & 113 & 224.23 & 996 & 22.51 & 0.58 & 3.08 & $1.05 \times 10^{19}$ \\
\hline
\end{tabular}

Table 3. XRD data of 40 minutes of exposed $\mathrm{Al}$ sample

\begin{tabular}{|c|c|c|c|c|c|c|c|c|c|}
\hline Peak No. & $2 \theta$ (degree) & $d, \AA$ & $h k l$ & $I$ & $I(\max )$ & $I$ (rel) & FWHM & G.S, $\AA$ & DLD \\
\hline 1 & 38.76 & 2.311 & 111 & 845 & 845 & 100 & 0.47 & 3 & $1.11 \times 10^{19}$ \\
\hline 2 & 45 & 2.013 & 002 & 178 & 845 & 21.07 & 0.52 & 2.88 & $1.20 \times 10^{19}$ \\
\hline 3 & 65.25 & 1.428 & 022 & 640 & 845 & 75.74 & 0.37 & 4.45 & $5.06 \times 10^{18}$ \\
\hline 4 & 78.25 & 1.220 & 113 & 784 & 845 & 92.78 & 0.43 & 4.15 & $5.80 \times 10^{18}$ \\
\hline
\end{tabular}

The data for the micro-hardness of the untreated sample as a function of time is represented by points in the figure. The hardness value of the unexposed sample is observed to be 168.5 (HV). However, the hardness value after 20 and 40 minutes exposure to radiation is 212.7 , and 349.9 (HV), respectively.

An increase in the value of hardness is observed with the increasing time of the irradiation. This variation in micro-hardness is due to microstructural defects. The increase in micro-hardness may also be credited to increasing the time of irradiation. These results are in agreement to those of Jelani et al. (2013), who revealed the increasing trend of micro-hardness analysis [33]. They observed the variation of micro-hardness of excimer laser irradiated $\mathrm{Zr}$ as a function of laser fluence. Khaleeq-urRahman et al. (2010) reported the micro-hardness data of the unexposed sample as a function of depth [34]. They investigate the microhardness profile of $\mathrm{Al} 5086$ alloys samples irradiated in air and vacuum and found an increasing trend of hardness as a result of the increasing number of laser shots.

\section{CONCLUSIONS}

In summary, the influence of the CW diode laser on the surface, structural, and mechanical properties of $\mathrm{Al}$ in a laboratory environment are shown. The $\mathrm{Al}$ samples are irradiated and investigated for different exposure time using $532 \mathrm{~nm}$ wavelength using SEM, and XRD for the surface and structural morphology, respectively. The micrometer grain size, exfoliational sputtering, and crater are revealed from the SEM analysis. A significant appearance of the formation of the random microstructure is observed in the morphology of the surface structure. It is further noticed that the material is splashed out during the irradiation, which is attributed to the fact that laser produces thermal stresses, cracks, and surface roughness. An increase in the grain size with the increasing exposure time is observed from the XRD analysis. An increase in micro-hardness is investigated by increasing the time of laser exposure.

\section{Acknowledgments}

The authors acknowledge the National Textile University, Faisalabad, the Pakistan Institute of Nuclear Science and Technology, Islamabad, and the University of Engineering and Technology Lahore for providing us characterization facilities. Zaheer Ud Din also acknowledges the financial support of the Young Doctors Cooperation Fund, Qilu University of Technology (Shandong Academy of Sciences) (Grant No. 2019BSHZ006).

\section{REFERENCES}

1. Hung, N., Marion, M. Improved Formability of Aluminum Alloys using Laser Induced Hardening of Tailored Heat Treated Blanks Physics Procedia 39 2012: pp. 318-326. https://doi.org/10.1016/j.phpro.2012.10.044

2. Sataeva, N.E., Boinovich, L.B., Emelyanenko, K.A., Domantovsky, A.G., Emelyanenko, A.M. Laser-Assisted Processing of Aluminum Alloy for the Fabrication of Superhydrophobic Coatings withstanding Multiple Degradation Factors Surface and Coatings Technology 397 2020: pp. $125993-126002$. https://doi.org/10.1016/j.surfcoat.2020.125993

3. Merklein, M., Böhm, W., Lechner, M. Tailoring Material Properties of Aluminum by Local Laser Heat Treatment Physics Procedia 39 2012: pp. 232-239. https://doi.org/10.1016/j.phpro.2012.10.034

4. Rathod, M., Deore, H. Laser Surface Hardening of Ductile Irons SAE Technical Papers 42014. 
https://doi.org/10.4271/2014-28-0021

5. Heinz, A., Haszler, A., Keidel, C., Moldenhauer, S., Benedictus, R., Miller, W. Recent Development in Aluminium Alloys for Aerospace Applications Materials Science and Engineering: A 280 (1) 2000: pp. 102-107. https://doi.org/10.1016/S0921-5093(99)00674-7

6. Sheasby, P.G., Pinner, R. The Surface Treatment and Finishing of Aluminium and Its Alloys. ASM international, Ohio, 2001.

7. Vesel, A., Drenik, A., Elersic, K., Mozetic, M., Kovac, J., Gyergyek, T., Stockel, J., Varju, J., Panek, R. BalatPichelin, M. Oxidation of Inconel 625 Superalloy upon Treatment with Oxygen or Hydrogen Plasma at High Temperature Applied Surface Science 305 2014: pp. $674-682$.

https://doi.org/10.1016/j.apsusc.2014.03.160

8. Chae, J.M., Lee, K.O. Amanov, A. Gradient Nanostructured Tantalum by Thermal-Mechanical Ultrasonic Impact Energy Materials 11 (3) 2018: pp. 452-469. https://doi.org/10.3390/ma11030452

9. Amanov, A., Umarov, R. Amanov, T. Increase in Strength and Fretting Resistance of Alloy 718 using the Surface Modification Process Materials 2018: pp. $1366-1379$. https://doi.org/10.3390/ma11081366

10. Kadlečková, M., Minařík, A., Smolka, P., Mráček, A., Wrzecionko, E., Novák, L., Musilová, L. Gajdošík, R. Preparation of Textured Surfaces on Aluminum-Alloy Substrates Materials 12 (1) 2019: pp. 109-121. https://doi.org/10.3390/ma12010109

11. Vora, H.D., Dahotre, N.B. Laser Surface Heat Treatment and Modification Advanced Materials \& Processes 171 (11) 2013: pp. 45-47.

https://www.asminternational.org/search//journal_content/56/10192/6072498/PERIODICALARTICLE

12. Kuznetsov, G.V., $\quad$ Feoktistov, D.V., $\quad$ Orlova, E.G., Batishcheva, K. Ilenok, S.S. Unification of the Textures Formed on Aluminum after Laser Treatment Applied Surface Science 469 2019: pp. 974-982. https://doi.org/10.1016/j.apsusc.2018.11.046

13. Pakieła, W., Tanski, T., $\quad$ Brytan, Z., Chladek, G. Pakiela, K. The Impact of Laser Surface Treatment on the Microstructure, Wear Resistance and Hardness of the AlMg5 Aluminum Alloy Applied Physics A 126 (3) 2020: pp. $231-240$. https://doi.org/10.1007/s00339-020-3350-x

14. Borisova, E.M., Gilmutdinov, F.Z., Reshetnikov, S.M., Chausov, F.F., Kharanzhevsky, E.V. Pisareva, T.A. Effect of Laser Treatment and Hydrophobization on the CorrosionElectrochemical Behavior of Aluminum Inorganic Materials: Applied Research 11 (3) 2020: pp. 520-525. https://doi.org/10.1134/S2075113320030065

15. Nassar, A., Taha, M.A., Saadallah, F.A. Surface Hardening of Hypereutectic Al-Si Alloy Treated by Nd: YAG Laser Middle East Journal of Applied Sciences 5 (05) 2015: pp. 31-35.

http://www.curresweb.com/mejas/mejas/2015/MEJAS\%20S pecial\%20Oct-Dec\%202015/31-35.pdf

16. Hussein, H.T., Kadhim, A., $\quad$ Al-Amiery, A.A., Kadhum, A.A.H., Mohamad, A.B. Enhancement of the Wear Resistance and Microhardness of Aluminum Alloy by Nd: YAG Laser Treatment The Scientific World Journal 2014 2014: pp. 842062-842066. https://doi.org/10.1155/2014/842062
17. Pinto, M.A., Cheung, N., Ierardi, M.C.F., Garcia, A. Microstructural and Hardness Investigation of an AluminumCopper Alloy Processed by Laser Surface Melting Materials Characterization 50(2-3) 2003: pp. 249-253. https://doi.org/10.1016/S1044-5803(03)00091-3

18. Almuslet, N.A., Alshake, A.A. Hardening Enhancement for Carbon Steel using High Power $\mathrm{CO}_{2}$ Laser Journal of Multidisciplinary Engineering Science and Technology 2 2015: pp. 9-13.

https://www.jmest.org/wpcontent/uploads/JMESTN42350304.pdf

19. Elkandari, B. Excimer Laser Surface Melting Treatment on 7075-T6Aluminium Alloy for Improved Corrosion Resistance. PhD Thesis, The University of Manchester, United Kingdom, (2013).

20. Montealegre, M., $\quad$ Castro, G., $\quad$ Rey, P., $\quad$ Arias, J., Vázquez, P. González, M. Surface Treatments by Laser Technology Contemporary Materials 1(1) 2010: pp. $19-30$. https://doi.org/10.5767/anurs.cmat.100101.en.019M

21. Nayak, S. Laser Induced Surface Modification of Aluminium Alloys. PhD Thesis, University of Tennessee, Knoxville, (2004).

22. Zhang, J., Huang, T., Mironov, S., Wu, Q., Zhang, Q., $\mathbf{X u}$, J. Xiao, R. Microstructure Evolution during Laser Pressure Welding of Pure Aluminum Materials Letters 260 2020: pp. $126931-126933$. https://doi.org/10.1016/j.matlet.2019.126931

23. Montross, C.S., Wei, T., Ye, L., Clark, G. Mai, Y.W. Laser Shock Processing and Its Effects on Microstructure and Properties of Metal Alloys: A Review International Journal of Fatigue 24 (10) 2002: pp. 1021-1036. https://doi.org/10.1016/S0142-1123(02)00022-1

24. Bashir, S., $\quad$ Farid, N., $\quad$ Mahmood, K., $\quad$ Rafique, M.S. Influence of Ambient Gas and Its Pressure on the laserInduced Breakdown Spectroscopy and the Surface Morphology of Laser-Ablated Cd Applied Physics A 107 (1) 2012: pp. $203-212$. https://doi.org/10.1007/s00339-011-6730-4

25. Krstulović, N., Labazan, I., Milošević, S. Study of Mn Laser Ablation in Methane Atmosphere The European Physical Journal D 37 (2) 2006: pp. 209-215. https://doi.org/10.1140/epjd/e2005-00285-3

26. Farid, N., Bashir, S. Mahmood, K. Effect of Ambient Gas Conditions on Laser-Induced copper Plasma and Surface Morphology Physica Scripta 85 (1) 2011: pp. 015702-015708. https://doi.org/10.1088/0031-8949/85/01/015702

27. Preuss, S., Demchuk, A., Stuke, M. Sub-Picosecond UV Laser Ablation of Metals Applied Physics A 61 (1) 1995: pp. 33-37. https://doi.org/10.1007/BF01538207

28. Pedraza, A., Fowlkes, J. Lowndes, D. Laser Ablation and Column Formation in Silicon under Oxygen-Rich Atmospheres Applied Physics Letters 77 (19) 2000: pp. 3018-3020. https://doi.org/10.1063/1.1324732

29. Mahmood, K., Farid, N., Ghauri, I., Afzal, N., Idrees, Y., Mubarik, F. Effects of Laser Irradiation on the Mechanical Response of Polycrystalline Titanium Physica Scripta 82 (4) 2010: pp. 045606-045612. https://doi.org/10.1088/0031-8949/82/04/045606

30. Cullity, B.D. Answers to Problems: Elements of X-ray Diffraction. Addison-Wesley Publishing Company, California, 1978. 
31. Chanda, M. Science of Engineering Materials: Volume 1: Structure of Matter. Palgrave Macmillan, London, 1981.

32. Yousaf, D., Bashir, S., Akram, M., Kalsoom, U.I., Ali, N. Laser Irradiation Effects on the Surface, Structural and Mechanical Properties of Al-Cu Alloy 2024 Radiation Effects and Defects in Solids 169 (2) 2014: pp. 144-156. https://doi.org/10.1080/10420150.2013.834901

33. Jelani, M., Bashir, S., Rehman, M.K.U., Ahamad, R., Yousaf, D., Akram, M., Afzal, N., Chaudhry, M.U., Mahmood, K., Hayat, A. Effect of Laser Fluence on
Surface, Structural and Mechanical Properties of $\mathrm{Zr}$ after Irradiation in the Ambient Environment of Oxygen The European Physical Journal D 67 (8) 2013: pp. 159-166.

https://doi.org/10.1140/epjd/e2013-30767-4

34. Khaleeq-ur-Rahman, M., Butt, M., Samuel, A. Siraj, K. Investigation of Laser Irradiation Effects on the Hardness of Al 5086 Alloy under Different Conditions Vacuum 85 (3) 2010: pp. $474-479$. https://doi.org/10.1016/j.vacuum.2010.08.025 provided you give appropriate credit to the original author(s) and the source, provide a link to the Creative Commons license, and indicate if changes were made. 